\title{
Anilla o de lo burlesco \\ (BL, núm. 682)
}

\author{
Alessandro Martinengo \\ Università di Pisa \\ Via Zamenhof, 10. \\ 56127 Pisa \\ Italia \\ martinengo9@gmail.com
}

[La Perinola, (Issn: 1138-6363), 22, 2018, pp. 189-198]

DOI: $10.15581 / 017.22 .189-198$

Me estoy empeñando por segunda vez en un espacio relativamente breve de tiempo, y con los debidos miramientos, en la interpretación del difícil romance burlesco de Quevedo "Anilla, dame atención». La primera vez intervine a través de un artículo en La Perinola de 2005², en donde, renunciando desde luego al examen del poema en su conjunto, limité mis consideraciones al que ahora, decidiéndome al contrario por un análisis del romance en su globalidad, llamaré fragmento o bloque a (vv. 5-168), al que haré seguir el examen tanto del que llamo bloque в (vv. 169-300) como de los dos fragmentos en que culmina el discurso metapoético del texto, y que funcionan respectivamente de incipit (vv. 1-4) y de explicit (vv. 301-304).

En 2005 lo que había llamado mi atención, en el fragmento considerado, era el evidente paralelismo narrativo entre las peripecias burlescas de Sansón y las de Hércules y, todavía más, lo excepcional del acercamiento, en la poesía quevediana de este género, de personajes pertenecientes a la mitología clásica y a la Biblia, respectivamente ${ }^{2}$. También había ensayado un cotejo entre BL 682 y el romance anónimo Las columnas de cristal que Astrana encontrara en el ms. 3796 de la BNE y publicara (Obras en verso, pp. 291-292) como inédito quevediano (incluso fechándolo en 1605), y Amédée Mas había cotejado con otro muy parecido (ms. 3795 de la misma BNE), pero dotado de variantes de interés (ninguno de los dos textos ha sido incluido en las ediciones

1. Martinengo, 2005.

2. Naturalmente los personajes bíblicos que se encuentran en la poesía burlesca del autor pertenecen casi todos al Antiguo Testamento, y su elección depende en gran medida del carácter proverbial o antonomástico que tradicionalmente se les ha atribuido. Sirva de ejemplo el caso de Salomón, citado en BL 768, v. 113, junto con la «hija del Faraón», v. 119, de Absalón, citado en BL 385, v. 43, y naturalmente de Dalila en el romance que estudiamos, v. 75 . 
recientes de Quevedo). Mas había tomado sus distancias frente a las interpretaciones que del texto anónimo habían dado Otis H. Green, arriesgando una comparación con Hemingway, y Lara Garrido, quien atribuía a la descripción del éxtasis amoroso, en el final del texto, alcance casi metafísico ( la visión cósmica del cuerpo femenino permite intensificar los espasmos voluptuosos hasta darles las dimensiones de una catástrofe natural»). Mas, al contrario, había certeramente sugerido, en casos como este, la necesidad de «descendre du cosmique au grivois» ${ }^{3}$.

Y finalmente, ya en 2005, había puesto de relieve las numerosas metáforas erótico-geográficas del anónimo, verbigratia:

\author{
Corrió el Amor las cortinas \\ que tuvo siempre cubiertas, \\ descubriendo maravillas \\ y otro Nuevo Mundo en ellas. \\ Hechos Colones mis ojos, \\ tendió la vista sus velas... \\ Vi dos montañas de plata (vv. 9 y ss.),
}

que me habían parecido chocantes (y más me lo parecen hoy) y del todo incongruentes respecto al tono burlesco medio-bajo, y a ratos matizado de rasgos afectivos, de chistes e inocentes facecias, del romance quevediano. A manera de resultado conclusivo de mis consideraciones de entonces, y sin perjudicar el análisis que va a seguir, sugiero la compararación entre los versos indudablemente muy explícitos que acabo de citar y aquellos, también de sabor geográfico, pero de extraordinaria levedad y fineza, que el locutor de вL 682 dedica a una de las hazañas de Hércules, llamándolo "ganapán del non plus ultra / y esportillero de rocas» (vv. 107-108).

Dejando finalmente de lado estas consideraciones de tiempos atrás y concentrándome en el análisis del romance en su globalidad, propongo su formalización, ya lo he anticipado, en dos bloques o fragmentos, $\mathrm{A}+\mathrm{B}$, que forman el corpus mayor del texto, del que habrá que distinguir los dos cuartetos extremos del texto mismo, el incipit y el explicit.

En el bloque o fragmento a (vv. 5-168) el locutor presenta conjuntamente, como ya sabemos, a los dos jayanes, el bíblico y el clásicomitologico ${ }^{4}$. Se trata de dos figuras de sexo masculino, víctimas del desprecio y la crueldad, rayanos en sadismo sexual, de sus respectivas amantes, Dalila en el caso de Sansón y Yole en el caso de Hércules, a la cual se añade Deyanira, otra enamorada o esposa (según las distin-

3. Mas, 1957, pp. 292 y 384-386; Lara Garrido, 1997, p. 61; Martinengo, 2015, pp. 145-147, donde ya me refería al romance вь 682.

4. En nuestro romance se le llama jayán a Hércules en el v. 136. En cuanto a Sansón, no se le llama de este modo aquí, sino por ejemplo en el idilio BL 385 (Celebra el cabello de una dama, que habiéndosele mandado cortar en una enfermedad, ella no quiso): (Y en ti el perdello / viniera en los sucesos a imitarle [a Sansón] / pues murieran en él cuantos le vieron, / como el jayán los que estuvieron» (vv. 45-48). 
tas versiones) del jayán clásico. Aludiendo burlonamente a la Biblia y a los casos de Sansón (Jueces, 16, 21), dice el locutor que los filisteos «sacáronle los dos ojos» y añade de su costal, introduciendo el motivo de la codicia y avidez femeninas (por otra parte ya presente en Jueces, 16,5 , al relatar la recompensa que los filisteos prometieran a Dalila si le cortara a su amante el cabello en que consistía su fuerza): (y sospecha cierta glosa / que se los había sacado / la tal por galas y joyas») (vv. 4144). En cuanto a Hércules, el sadismo de sus amadas resulta aún mayor, en especial modo el de Yole: decidida a degradar al jayán al rango de mujerzuela, al nivel en suma de sus criadas y esclavas, la muchacha se ve obligada, dadas las medidas excepcionales de su víctima, a hiperbolizar en extremo las señas del sometimiento y ridiculización de este:

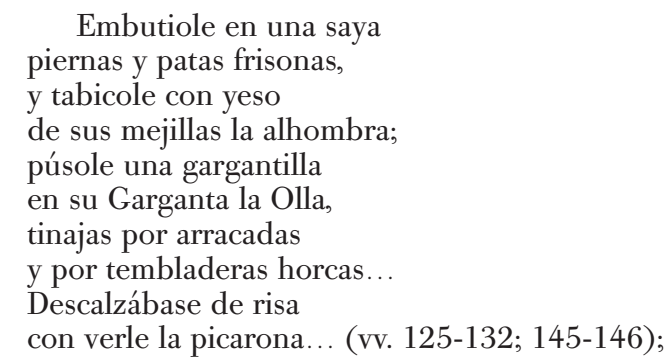

en cuanto a las crueldades de Deyanira, dice el locutor:

De celos de estas finezas

otra maldita mondonga

una camisa le viste

teñida con peste y roña (vv. 153-156) ${ }^{5}$.

En oposición total, el bloque в (vv. 169-300) presenta una serie de personajes mitológicos todos de sexo femenino, a las cuales sus pretendientes, dos de los mayores dioses del Olimpo, Apolo y Júpiter -y naturalmente el locutor, dentro de los confines de lo burlesco y de la

5. Respecto a las humillantes desventuras de Hércules, como a las demás referencias mitológicas del romance, punto de referencia básico han sido para Quevedo las Metamorfosis de Ovidio, como mejor veremos más adelante; pero también la Philosofía secreta de Juan Pérez de Moya ha jugado un papel importante: por ejemplo, al relatar el episodio de Deyanira mandando a Hércules vista la prenda empapada de la sangre de Neso, y por lo tanto portadora de muerte, Ovidio emplea siempre la palabra vestis («inbutam Nesseo sanguine vestem / mittere), Metamorfosis, IX, vv.153-154), mientras en la Philosofia secreta (Pérez de Moya, 1995, p. 465) se lee la traducción castellana de la palabra, que ofrecerá a Quevedo la ocasión para las numerosas divagaciones burlescas que ocupan los vv. 153-164 de nuestro romance: «Nesso [...], desnudándose su camisa de la herida muy ensangrentada, la dio a Deyanira». De ahí, entre otras pullas, la alusión de nuestro locutor a la codicia de Anilla: “Murió el asnazo en camisa. / Aplicalo, Anilla, agora, / pues en camisa me dejan / tus embestiduras sordas» (vv. 157-160. Subrayo yo). 
chanza-, tratan de manera apasionada y a ratos matizada de rasgos afectivos o eróticos: así Apolo galantea a Dafne (vv. 169-188), Júpiter a Dánae, Leda, Ío y Europa (vv. 121-268). Sigue y concluye la enumeración, algo sorprendentemente, el homérico raptor de Elena, y juez -en el monte Ida- de la belleza respectiva de las tres diosas Venus, Juno y Minerva, es decir Paris; aunque su presencia no desdice, en realidad, de la compañía femenina en que se le pone, puesto que su sexualidad resulta ambigua, al menos según Ovidio, quien lo define «raptor cobarde de la Griega» y asesino de Aquiles a pesar de sus «fuerzas femíneas» ${ }^{6}$. Ya veremos en lo que sigue cómo la presencia de Paris no es casual, sino que sus atributos funcionan de punto de arranque para el final metaliterario y de alcance subversivo del poema.

Sin embargo, profundizando en el asunto, considero indispensable abordar otro posible nivel de lectura del romance, que me parece aventajarse al propuesto hasta ahora (con su división en los dos bloques a y в), salvando en todo caso el relieve especial del incipit y del explicit. En efecto, procediendo por este nuevo camino, veremos cómo cada fragmento del poema dedicado a cada una de las respectivas figuras míticas se compone de dos subfragmentos de extensión desigual y a veces no perfectamente deslindables que, adoptando la venerable terminología que se remonta a Gonzáles de Salas ${ }^{7}$, se coloca, el primero, en el plano de las burlas, añadiendo, el segundo, una ponderación que corresponde al plano de las veras.

Podemos adelantar que el propósito de las veras es siempre el de censurar, con mayor o menor severidad, la codicia de Anilla, su intransigencia en pedir dinero y joyas a su amante, en última instancia, su inconformidad con respecto a un comportamiento social normal; mientras que el espacio de las burlas se atiesta de estilemas donairosos, chistes lingüísticos y facecias, de tono en suma jocoserio (invocando una vez más la autoridad de don Jusepe Antonio) ${ }^{8}$, matizado de rasgos de apasionamiento y a veces casi de cariño por la muchacha, «aventajándola a todas», como se expresa el título del poema.

Pongamos el ejemplo de Sansón y de la matanza que hizo de filisteos en la ruina de la sinagoga, en donde, tras las burlas del comienzo, en el v. 73 empiezan las veras:

6. Ver Metamorfosis, XII, 607-610: “Tantorum victor, Achille, / victus es a timido Graiae raptore maritae. / At si femmineo fuerat tibi Marte cadendum"' 'Te venció, Aquiles, que a tantos venciste, el cobarde raptor de la esposa griega. Si estabas pues destinado a morir por mano de una hembra?.

7. Fasquel, 2011, p. 127: «S’il y a bien une poétique du burlesque [en el Siglo de Oro], aucun texte ne cherche à la définir, à en systématiser les traits caractéristiques, comme on cherchait à la même époque à définir le poème épique ou la tragédie. On ne peut donc guère compter que sur la dissertation de González de Salas [Parnaso, pp. 407-411], dont nous avons signalé la singularité dans le panorama critique». Con anterioridad a este libro fundamental, un trabajo de referencia obligada era Bertrand, 1998.

8. Me refiero, citando a González de Salas, a Parnaso, pp. 399 y 408 respectivamente. 
Pues, Anilla, verbi gratia, si a las fuerzas más famosas rindió Dalila en Sansón, siendo blanca, rubia y roma, ¿qué defensa tendré yo contra ti, que eres Sansona de la belleza, que a la alma con luces y rayos corta, aguileña y pelinegra? ¿Y en qué pecho no harán roncha esos dos ojos jiferos de la carda y de la hoja? ¿Cómo de tu boca, oriente que está chorreando auroras, podrán escapar mis rentas sin salir trasquilimochas? (vv. 73-88).

Otro fragmento a considerar sería el de Dafne, perseguida por Apolo, fragmento que ve entremezclarse, en el amplio espacio de las burlas, todos los topoi jocoserios del arsenal de don Francisco:

Si la luz trujo arrastrando como otros suelen la soga tras Dafne el Sol, cuadrillero con más saetas que joyas;

$$
[\ldots]
$$

y si en competencia tuya [de Anilla]

era Dafne carantoña,

ninfa que los escabeches y las aceitunas ronda, siendo tú el Sol, icon cuál ansia volaré yo cuando corras!, pues con las alas del viento pensaré que llevo cormas (vv. 169-184).

Las veras en este caso están concentradas en el último cuarteto del fragmento, donde se hace referencia a dos árboles útiles, según apunta Arellano en el comentario que me ha cortésmente facilitado (e irá a formar parte de la esperada edición del entero poemario de don Francisco, de inminente aparición):

No te transformes en árbol, mas si en árbol te transformas acuérdate del ciruelo y del que lleva bellotas (vv. 185-188) ${ }^{9}$.

9. Naturalmente el citado comentario de Arellano es mi constante punto de referencia, y no solo en este caso. Sin embargo, se podría insinuar que ni siquiera en las veras se escatiman aquí las alabanzas, al menos indirectas, de Anilla, a la cual se pide transfor- 
Aún más amplio es el espacio dedicado a las burlas en los dos episodios contiguos de Dánae (que engloba también los casos de Leda e Ío $)^{10}$ y Europa; en el primero, donde predomina pour cause el tema del dinero y de la corrupción femenina (para seducir a la mujer Júpiter “bajó en contante del cielo / y a lo mercader negocia»)" ${ }^{11}$, las veras reduciéndose aquí también a un solo cuarteto, que el locutor dirige a Anilla:

\author{
¿con cuánta mayor razón \\ me desharé en lluvia roja \\ sobre tus faldas, y en minas \\ podrás decir que me cobras? (vv. 217-220).
}

En cuanto al fragmento concerniente al rapto de Europa por parte de Júpiter transformado en toro, la porción del texto dedicada a las burlas adquiere la extensión de una especie de larga alegoría, con momentos de sumo esparcimiento, cuando el locutor aprovecha la ocasión para insertar humorísticas alusiones a las costumbres contemporáneas, las fiestas de toros (vv. 229-236) y los paseos en carrozas por el Prado, que tanta preocupación suscitaban en los guardianes de la pública moral (vv. 237-240). El trozo también contiene pasajes de dificil interpretación como el siguiente, que alude a la navegación del toro hacia Creta:

Hízose [el toro] nave cornuda, hizo la cabeza popa, de sus cabellos [de la joven] la vela y de sus ancas la proa (vv. 245-248).

Creo que el cuarteto contiene una suerte de curioso retruécano, y hay que tratar de conciliar la idea de un camino hacia adelante, como el del toro raptor ${ }^{12}$, con los indicios que da el texto de un camino aparen-

marse, en lugar del socorrido laurel, en ciruelo, cuyo fruto de color amarillo, la ciruela, lo alaba Virgilio en la segunda égloga por «tener el color de los enamorados» (ver Cov., 2006, s.v.). En cuanto a la bellota, fruto del roble, era, como es bien conocido, el alimento favorito en la mítica Edad de Oro. ¿Dos piropos más en honor de Anilla?

10. Se refieren a Ío los vv. 209-212 (ya lo había señalado Astrana en Obras en verso, pp. 290-291): «Pagó [Júpiter], cual si fuera invierno / en niebla a otra dormilona, / y de puro bien mojada /quedó buena para sopa». Ovidio (Metamorfosis, I, vv. 597-600) narra la manera cómo Ío, amada de Júpiter y transformada en vaca por los celos de Juno, había sido seducida por el dios: «Fugiebat enim. Iam pascua Lernae / consitaque arboribus Lyrcea reliquerat arva, / cum deus inducta latas caligine terras / occuluit tenuitque fugam, rapuitque pudorem) ("Huía, y ya había dejado los pasturajes de Lerna y las arboledas del Lirceo, cuando, ocultada con una densa niebla una larga porción del camino, el dios paró su fuga y le quitó el honor').

11. Al tratamiento quevediano de la historia de Dánae he dedicado el artículo Martinengo, 2006.

12. Creo que Quevedo ha tenido presente la larga tradición pictórica que, a partir de Durero, llega a su predilecto Tiziano (uno de los lienzos de este, o poesie, precisamente el Rapto de Europa, lo envió el pintor al futuro Felipe II, y era conocidísimo en España) y a Giulio Romano por lo menos. Ahora bien, en esta tradición iconográfica se representa 
temente hacia atrás («hizo la cabeza popa», v. 246): la base del juego estaría en la acepción que da Aut, s. v., de la palabra popa como «asiento que mira hacia delante» (en los carruajes antiguos), mientras que a proa se debería, por capricho conceptista de intercambiar imágenes en oposición, atribuir el sentido contrario ${ }^{13}$. En cuanto a las veras, que siguen como de costumbre, ellas contienen en realidad una apasionada alabanza de la destinataria, matizada tan solo por una leve e indirecta alusión a su codicia (el miércoles corvillo):

por ti [Anilla] que retas los signos

con los que cierne tu cofia,

cuyo talle y cuyo brío,

no es nísperos lo que mondan,

convertireme en ceniza,

pues tus soles me abochornan,

aunque el miércoles corvillo

entre las cejas me ponga (vv. 269-276).

Y vengamos por fin a Paris quien, según decíamos, ocupa el último lugar en el elenco de las ninfas ${ }^{14}$ por haberle tildado Ovidio de cobarde y de escasa virilidad. Pero no debe solo a esto la posición clave que, en

siempre a Europa recostada en las espaldas del toro (que nada hacia adelante), mirando con melancolía hacia atrás, a las compañeras de los juegos interrumpidos. Los pintores se inspiraban en un breve pasaje de Ovidio, Metamorfosis, vi, vv. 105-107, caracterizado por un detalle enternecedor («ipsa videbatur terras spectare relictas / et comites clamare suas tactumque vereri / adsilientis aquae timidasque reducere plantas' 'Se veía a Europa mirar hacia la orilla abandonada e invocar a sus compañeras, retirando los pies por temor a las olas'). Para mí no hay duda pues acerca de la imagen que, prescindiendo del bizarro juego conceptista aludido, se hacía el poeta de la escena del rapto. Ver Passerini, 2002, (donde se encuentra una amplia documentación iconográfica sobre el tema). Verdad es que existe otra versión del cuento mítico y a ella se refiere Antonio Gargano comentando, en su reciente artículo (2016, p. 45), los versos 41-42 de las décimas BL 673 («Si a Júpiter, toro o popa / bramar y nadar le vieras»): el crítico se refiere a la nota marginal que acompaña dichos versos en algunos manuscritos: Alude a la transformación en toro que los mitológicos dicen que fue nave que tenía por imagen tutelar un toro». Creo que se trata de una racionalización tardía del mito, recogida, por ejemplo, por Pérez de Moya, 1995, p. 555); supone la atribución a popa del sentido de 'nave' y, en el caso del romance de Anilla, no resuelve sino que complica la interpretación del texto.

13. No creo necesario suponer que en los vv. 265-268 se aluda al mito de Pasifae, sino que se sigue hablando del de Europa.

14. Quevedo llama ninfas a los personajes mitológicos menores de sexo femenino. Ver, además del v. 289 de nuestro texto, el romance BL, 768, donde, además de a muchos otros seres mitológicos tratados de manera muy parecida al texto que comentamos, se hace referencia a «las ninfas metamorfosias» de la gentilidad (v. 122). Metamorfosias es en este caso adjetivo; en nuestro romance, v. 294, es sustantivo (cuantas metamorfosias), y es verbo en el soneto anti-gongorino BL, 838 ¿Qué captas, noturnal, en tus canciones...?, v. 14: «metamorfoseando el arcadumia». Aprovecho para notar que en otro soneto del mismo intento polémico, Sulquivagante, pretensor de estolo, Apolo huye de Dafne en lugar de perseguirla («Huye, no carpa de tu Dafne Apolo», v. 5), a diferencia de lo que ocurre en los famosos sonetos BL 236 y 237, en los cuales se concentran todos los topoi satíricos que encontramos en Anilla dame atención, vv. 170 y ss. 
mi opinión, adquiere en el romance al motivar y dar pleno sentido a su final metaliterario: Paris es también el que los mitólogos afirman haber sido escogido como juez para dirimir la disputa de las tres diosas sobre su respectiva belleza.

En nuestro romance se le define burlonamente, en efecto, «el catarribera» (v. 277). Catarribera: dice Aut, s.v., que «en la corte se llaman así los abogados que se aplican a salir a pesquisas y otras diligencias semejantes», autorizando esta particular acepción tanto con la referencia al romance que comentamos como a un pasaje muy explícito del Soldado Pindaro, que reza: «Llámanlos en la corte Bártulos en docena, Baldos de toda broza, y en general catarriberas». Una apreciación de claro sentido despreciativo $^{15}$. E igualmente se lee en el DRAE, s.v.: “abogado indocto, charlatán e ignorante. Rábula».

A pesar de presentarlo pues como personaje despreciable, o quizás justamente por ello, a Paris lo utiliza nuestro locutor como pivote alrededor del cual gira, lo hemos anticipado, su discurso metaliterario: la afirmación paradójica del carácter subversivo de lo burlesco. La argumentación se desarrolla por fases sucesivas, cuyo eje es en todo caso el valor (como siempre a doble faz, negociante y erótico) de Anilla. Bajo el primer aspecto, de hecho, las «lonjas» de la muchacha (interpreto, sus industrias gananciosas) valen, es decir, tienen más poder que todas las posibles reservas y cautelas de abogados o jueces, defensores de la estabilidad social:

pues barbas jurisjueces [se le dice] sabes gastar por escobas (vv. 291-292).

No basta: pasando a los atractivos personales de Anilla, un solo «bullicio»s suyo vale más

que cuantas metamorfosias

en las cañas flautas silban

y en las abubillas roncan (vv. 294-296),

es decir, sus atributos eróticos valen más que el entero universo poemático de Ovidio y, en última instancia, más que el entero patrimonio de la cultura alta tradicional ${ }^{16}$. El valor de Anilla se ejerce pues tanto a nivel de las burlas (arrolla y desbarata todo el conjunto de los mitos y de la

15. Los italianos hablaríamos de un azzeccagarbugli recordando al archifamoso abogado de Los Novios de Manzoni.

16. A estas alturas está reconociendo Quevedo que su principal punto de referencia han sido, en la concepción del romance, las Metamorfosis, en su doble vertiente pastoral y trágica: el v. 296 alude en efecto al mito de Pan y Siringa, según el cual la ninfa, perseguida por el dios, se transformó en la caña que Pan a su vez transformó en la flauta de los pastores; mientras que el v. 297 alude al mito de Tereo que, violador de su cuñada Filomela, fue transformado en la lúgubre abubilla, «dicha en griego epoph, de oi oi, quod gemens videtur dicere. Ovid. lib. 6 [v. 674] Mets (Cov., s.v.). 
cultura tradicional) como al de las veras (arrolla y desbarata todas las trabas sociales). Ella representa en una palabra el carácter fundamentalmente subversivo de lo burlesco, convirtiéndose en su símbolo.

Y para concluir, el propósito metaliterario culmina en el bloque formado por el incipity el explicit del romance, donde finalmente se traduce en poética al sugerir el locutor una retórica y una estilística adecuadas al 'nuevo' género: conjunto que sería tentador hacer coincidir con una suerte de manifiesto de lo burlesco ${ }^{17}$. En el incipit en efecto se le pide a Anilla escuche (a pesar de su inclinación por el dinero y los regalos) un mensaje gratis, de estilo humilde («musa cultipicaña), sintagma impreso en cursiva en Parnaso para subrayar su fuerte unidad) y tono despreocupado («se desabrocha»). En el explicit el mensaje se eleva (a pesar del tono bronco) al nivel de discurso de principio al afirmar el locutor, gracias a la parodia contundente del lenguaje 'oficial' ([le desmiento por la gola] $->$ (le desmiento por la potra» ${ }^{18}$ ), el estatuto del género burlesco frente a los cánones de la literatura y la sociedad elevadas:

Yo lo digo, y si dijere

algún filósofo en contra,

sin exceptar a ninguno,

le desmiento por la potra (vv. 301-304).

\section{Bibliografía}

Bertrand, Dominique, (ed.), Poétiques du burlesque. Actes du Colloque international du Centre de Recherches sur les Littératures Modernes et Contemporaines de l'Université Blaise Pascal, 1996, Paris, Honoré Champion, 1998.

BL $=$ Quevedo, Francisco de, Obra poética, ed. José Manuel Blecua, Madrid, Castalia, 1969-1981, 4 vols.

Cov = Covarrubias Horozco, Sebastián de, Tesoro de la lengua castellana o española, ed. Ignacio Arellano y Rafael Zafra, Pamplona / Madrid, Universidad de Navarra / Iberoamericana, 2006.

Fasquel, Samuel, Quevedo et la poétique du burlesque au XVII siècle, Madrid, Casa de Velázquez, 2011.

Gargano, Antonio, "Verdades diré en camisa". Comicidad y poder en la poesía burlesca de Quevedo», La Perinola, 20, 2016, pp. 17-51.

Lara Garrido, José, “Columnas de cristal. Códigos e interdiscursividad entre un soneto de Lope y un famoso romance anónimo", en El cortejo de Afrodita. Ensayos sobre literatura hispánica y erotismo, Málaga, Universidad de Málaga, 1997, pp. 23-68.

17. No olvidemos en efecto que González de Salas había colocado nuestro poema al comienzo de la serie romancística de la Musa Thalía, solo posponiéndolo al último texto de la tenzone poética entre Quevedo y Lerma, cuyo tema dominante es también la avaricia (Mandan las leyes de Apolo) y a una breve pieza teórica suya (Parnaso, pp. 478 y ss.).

18. Potra es, según Aut, s. v., una "especie de hernia o rotura interior, que se causa por bajar las tripas a la bolsa de los testículos». 
Martinengo, Alessandro, «Dos jayanes, el bíblico y el clásico, frente a la Pidona», La Perinola, 9, 2005, pp. 113-124.

Martinengo, Alessandro, Quevedo. Fronteras de la filología, con una mirada hacia Gracián, Pamplona, Eunsa, 2006.

Martinengo, Alessandro, Al margen de Quevedo. Paisajes naturales. Paisajes textuales, New York, Idea, 2015.

Mas, Amédée, La caricature de la femme, du mariage et de l'amour dans l'oeuvre de Quevedo, Paris, Ediciones Hispanoamericanas, 1957.

Ovidio Nasone, Publio, Le Metamorfosi, ed. Mario Scaffidi Abbate, Roma, Newton Compton Editori, 2011.

Pérez de Moya, Juan, Philosofia secreta, ed. Carlos Clavería, Madrid, Cátedra, 1995.

Pesserini, Laura, (ed.), Il mito d'Europa, Firenze, Giunti, 2002.

Quevedo, Francisco de, El Parnaso español, monte en dos cumbres dividido,... Poesías de don Francisco de Quevedo Villegas.. que salen de la Librería de don Ioseph Antonio González de Salas, Madrid, Diego Díaz de la Carrera, 1648.

Quevedo, Francisco de, Obras completas. Obras en verso, Madrid, Aguilar, 1952.

Quevedo, Francisco de, Obra poética, ed. José Manuel Blecua, Madrid, Castalia, 1969-1981, 4 vols. 


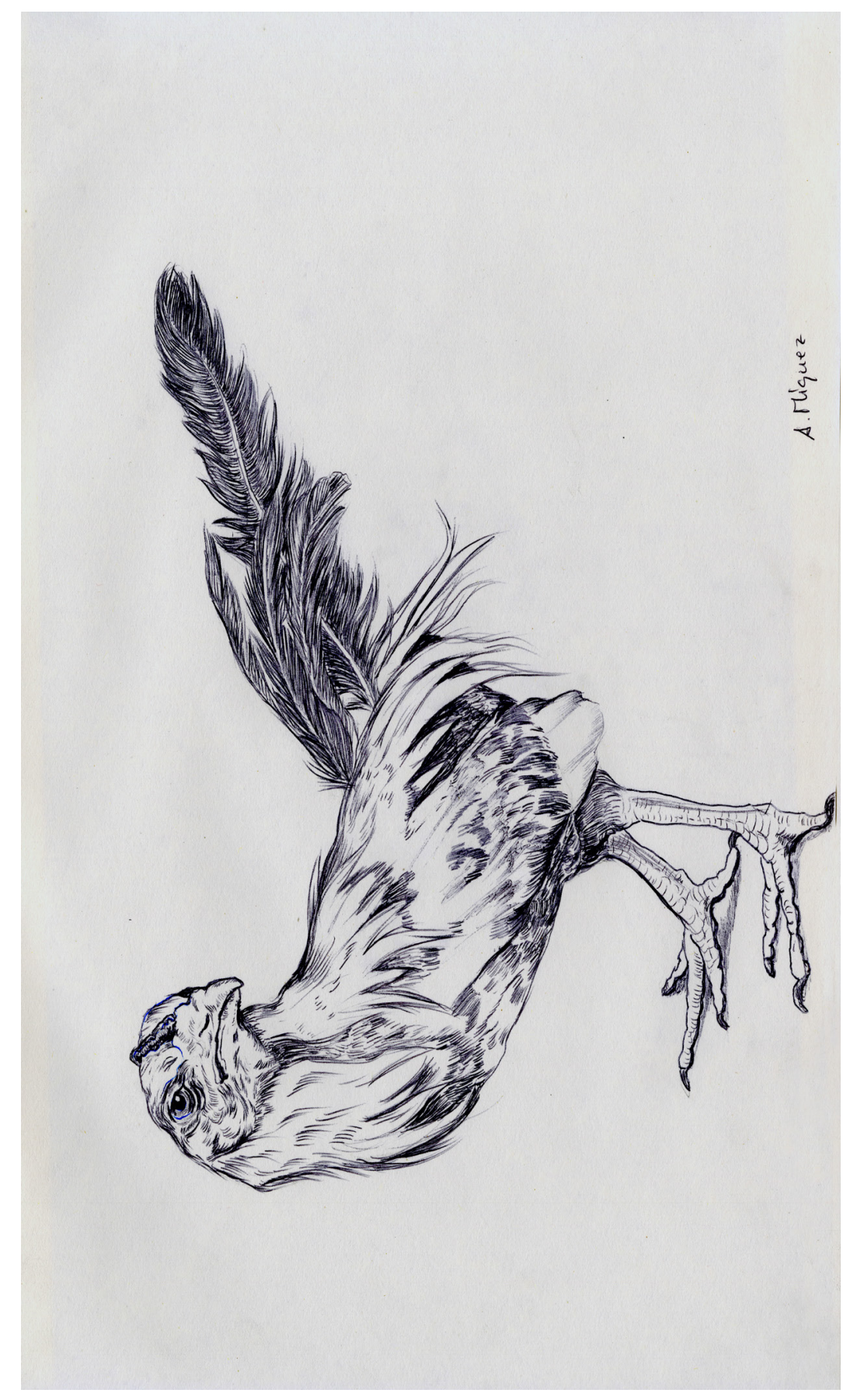


